\title{
APOLOGY STRATEGY IN ENGLISH BY NATIVE SPEAKER
}

\author{
Mezia Kemala Sari \\ Teacher Training and Education Faculty, \\ Muhammadiyah University, Sumatera Barat \\ Jalan Dt. Sinaro Panjang No. 35 Padangpanjang, Sumatera Barat 27121 \\ miss.mezia@gmail.com
}

Received: $16^{\text {th }}$ November 2015/ Revised: $22^{\text {nd }}$ February 2016/ Accepted: $1^{\text {st }}$ April 2016

How to Cite: Sari, M. K. (2016). Apology Strategy in English by Native Speaker. Lingua Cultura, 10(1), 13-17. http://dx.doi.org/10.21512/lc.v10i1.815

\begin{abstract}
This research discussed apology strategies in English by native speaker. This descriptive study was presented within the framework of Pragmatics based on the forms of strategies due to the coding manual as found in CCSARP (Cross-Cultural Speech Acts Realization Project).The goals of this study were to describe the apology strategies in English by native speaker and identify the influencing factors of it. Data were collected through the use of the questionnaire in the form of Discourse Completion Test, which was distributed to 30 native speakers. Data were classified based on the degree of familiarity and the social distance between speaker and hearer and then the data of native will be separated and classified by the type of strategies in coding manual. The results of this study are the pattern of apology strategies of native speaker brief with the pattern that potentially occurs IFID plus Offer of repair plus Taking on responsibility. While Alerters, Explanation and Downgrading appear with less number of percentage. Then, the factors that influence the apology utterance by native speakers are the social situation, the degree of familiarity and degree of the offence which more complicated the mistake tend to produce the most complex utterances by the speaker.
\end{abstract}

Keywords: apology strategies, English, native speakers

\section{INTRODUCTION}

Every day people talk or speak to variety of destinations. Speaking is the sharing of something and have the intent of the speaker. Ting-Toomey, et. Al. (2005) has stated that in every effective speech, there must be interrelatedness and mutual understanding between speaker and hearer.

At first, the speech act is the center of the study of pragmatic pioneered by philosopher Austin (1962), then continued to grow, until the theories related to speech acts appear, as Grice (1957), Searle $(1969 ; 1975 ; 1979)$, Leech (1983) and others.Broadly speaking, communication is not just a linguistic expression, but this is more on the use of expressions that accompanied the speech acts in it, such as: giving a statement, asking, ordering, thanking, apologizing and so on (Huang, 2007).

J.L. Austin (as cited in Nadar, 2009) said that basically speech act or acts in a pragmatic when someone says something, he does something, too. For example, the word of apologize in a speech, "I apologize for coming late", is relevant to the action of the speaker when he does it. These speeches are the performative speech with the performative verb.
The most important act in the study and understanding of speech acts is illocutionary acts. Acts of illocutionary are speech acts that do not only inform everything, but it can also be used to do something (the act of doing something). While perlocutionacts are actions to affect hearers such as humiliating, intimidating, cajoling, and so on. The speech is performed by speakers, and it has a power of influence (perlocutionary force) that cause effects intentionally or unintentionally (the act of affecting someone). Locutions acts are a speech act that merely says something (the act of saying something).

Nadar (2007) has said that a speech has a different function according to the situation. For example, an utterance can function as a regulator of the activities of others, such as: to govern, to express feelings, to reject, to approve, to ask for something and so on. Among the many examples of speech acts, there are one speech acts that have no less important role in communicating and certainly it is done by almost everyone, that is apology. Speech act of apology is important because it is needed to correct the mistakes that have been made, so as to improve the harmony between speaker and hearer.

An apology is an admission of responsibility by the speakers on the attitude, behavior, or failure to implement 
something (Smith, 2008). This speech act is face-saving for the listener and is a face-threatening for speakers. Ogierman (2009) has said that Searle put the apology speech act in expressive illocutionary classification that serves to reveal and express the psychological attitude of the speaker to the circumstances implied in illocutionary. As well as commissive illocutionary that is more focused on the hearer interests, an apology is an expressive utterance that tends to be enjoyable and less competitive, and therefore, intrinsically this illocutionary is polite. More precisely, Searle put the expressive and commissive illocutionary as a positive politeness that is different from the directive, which is negative politeness.

According to Blum Kulka and Olshtain (as cited in Ogiermann, 2009), there are five verbs other than the word "apologize". All five of these verbs are performative verbs that are included in apology strategy; the words are "regret", "excuse", "sorry", "forgive" and "pardon'. The expression of apology can be divided into an offer or apology as "I apologize", expression of regret like "I'm sorry", and request for forgiveness like "excuse me". All forms of explicit apology utterance are merged into one category that is IFID (Illocutionary Force Indicating Device) in which every utterance have the same meaning.

Apology strategy is divided into more specific, two general strategies, such as IFID and the expression of speaker's responsibility.Besides that, three specific strategies that could potentially appear according to the utterance situation, the explanation of the situation or account, offer of repair, and the promise of for bearance.All three of these strategies appear more often if the content or the circumstance trigger the emergence of this strategy or pattern. The emergence of intensification and also the efforts to diverse and downgrade situations or entertainment can serve to reinforce the narrative apology for the hearer.If intensification has a role in modifying IFID internally as the addition of adverbs like "really", "very", "so" and others as well as other expressions such as emotional expression like "oh", "oh my God" and so on. Meanwhile, downgrading has a role in adding strategy that usually appears at the end of the speech which aims to neutralize or diverse the state as a result of face threateningto speakers such as "I am sorry, but " or it could be an expression of humor, pretension, and so on.Another strategy that can occur is the concern to the hearer.

In addition, the role of language as the means of social communication would require the role of the principles of cooperation and courtesy to achieve successful communication. Basically, people communication will be subject to normative aspects in speaking. There are many examples of apology utterance in English that we often encounter with different social situations and hearers, such as:

"I am terribly sorry. It was an accident. I promise it won't happen again"

"I ' $m$ so sorry. I forgot to buy it. Let me buy it now for you. Don't worry"

"Excuse me Sir, this is my stop"

These pattern of speech acts commonly occurs and in general. The use of IFID words, like "sorry", "excuse me", "apologize" and so on is expressive speech markers that indicate someone is apologizing.

Basically, language is a reflection of culture through the speech of native speakers. Alfattah (2010) conducted a study on the strategy of the speech act of apology in EFL students at the University of Yemen. He found that IFID followed by responsibility was dominant. While Nuryanto (2010) stated that there is a tendency of respondents to use more than one strategy in apology, he found that the speech of apology was not always in the form of declarative but also interrogative. No rule requires a person to choose a particular strategy to speak. However, Blum Kulka et al. (as cited in Ogierman, 2009) in their project, CCSARP (CrossCultural Speech Acts Realization Project), concluded that there is universality in disclosing the speech of apology with the emergence of two the most potential strategies namely IFID followed by expression of responsibility. While the emergence of other strategies is due to the demands of the situation or based on the need.

Bataineh (2005), which conducts research on American students who also use manual coding in CCSARP found that the potential strategy that emerges is an expression of regret, clarification, and refinement. And it found that many similarities between male and female respondents. While Nureddeen (2008) in her research on the strategy of apology in Arab Sudan, found that IFID expression followed by an expression of responsibility and explanations is more frequently occurred in apology utterance.

Native speakers, like Americans, tend to speak briefly and to the point. This is evident from observations of the researchers in communicating with native speakers and in the literature or display about the life of native speakers. The possibility of a tendency to speak briefly and to the point has the potential to appear in the expression of apology by native speakers.

Based on the background of these problems, theoretically, this research is expected to provide a general description of the apology strategy by native English speakers. In addition, practical research is expected to add to the understanding of non-native English speakers to understand and learn the English language directly from native speakers, especially in expressing apology. The questions about how the pattern of apology strategies and affecting factors, can be the basis of this research and then analyzed by a pragmatic approach. In this case, a strategy that will be examined is the apology often used by native English speakers in a variety of situations and forms of the specific pattern.

\section{METHODS}

This study is conducted to acquire or obtain the desired results by using objective, not subjective, and scientific methods. Sudaryanto (as cited in Nadar, 2009) has stated that scientific research is a series of activities that aim to solve problems using the scientific method. Besides that,Mastoyo (2007) has explained that in the study of linguistics, data collection can be done by collaboration with researchers in the form of a conversation (face to face or not).

Research will be conducted descriptively with the pragmatic approach. At this stage of the provision of data, Discourse Completion Test (DCT) will be used by the questionnaire technique. The questionnaire has been designed by the social variables such as the level of familiarity and social status that contain descriptions of the daily situation. The questionnaire is prevalent, so it can be adjusted to live in America by involving participants from native speakers, as many as 30 people of Kentucky 
native, USA, at the age of 20-40 years old. Meanwhile, the discourse used in this study consisted of 12 different situations yet representing familiar and unfamiliar status, which are further subdivided based on their social distance, but the DCT is displayed at random.

According to Sudargo (as cited in Nadar, 2009), data is a special lingual phenomenon directly related to the problem in question. Thus, the data obtained in the questionnaire will be instantly analyzed.The analysis is based on the formulation of the problem, the objectives, and the basic theory. The data obtained will be analyzed and classified based on the division between native speakers and are not based on the strategy pattern that emerged from the calculation of the percentage of each strategy refers to the Manual Code.

\section{RESULTS AND DISCUSSIONS}

Not everyone has the same style in expressing apologies. The style is an utterance selection strategy that will be used to convey the idea to apologize. The style is a speech election strategy that will be used to convey the idea to apologize. Almost anyone who has ever made a mistake in everyday life, whether intentional or not, such as interfering with other people to ask or express something, forget something important for others, causing damage to an object for others, etc.

To be able to find the peculiarities of the apology selectionstrategy, then the role of the questionnaire that has been designed in such a way becomes very important. With the starting point to the sociolinguistic variables, then the classification of the data can be seen more clearly. The variables that are important in this case is the level of familiarity, which is familiar and not familiar and then it is divided by social status between the speaker $(\mathrm{S})$ and the hearer $(\mathrm{H})$, from a lower, equal and higher status.

There are several classification of apology strategies, such as IFIDs (Illocutionary Force Indicating Devices), Utterance of Responsibility, Explanation or Account to Situation, Offer of Repair, Promise of Forebearance, Alerters, Downgrading, and Concern for the Hearer.

IFIDs is a marker of an explicit apology in the form of a performative verb to express an apology like "Sorry", "Excuse me", "I apologize for", "Forgive me", "I regret that", "Pardon me" and so on. In addition, IFIDs tend to be accompanied by several markers of apology intensifier that modify IFID internally. The next strategy is Utterance of Responsibility explicitly states that Speaker had made mistakes to Hearer. This utterance in more detail consists of several types, namely: explicit self-blame, example "My mistake"; the utterance that do not mean to hurt Hearer or lack of intent, example "I did not mean to upset you"; Recognition of mistakes or admission of facts but not a responsibility, example "I forgot", "I have not read it"; justify hearer, example "You are right to be angry"; An expression of embarrassment, example "I feel awful about it"; and refuse to acknowledge guilt. While the strategy of Explanation or Account to Situation aims to elucidate further the causes or other factors associated with the occurrence of mistakes and is closely related to responsibility, for example: "the traffic was terrible", "my tutor kept me late" and so on.

If the mistakes of speaker could have the worse impact, then the other strategy, Offer of Repair, often appears to improve things such as "I'll pay it for you", "I'll fix it", and so on. Then, if the above strategies are not yet strong enough, then the strategy of Promise of Forbearance is also frequently used when it is required, like, "This will not happen again" to convince Hearer that this mistake will not happen again. This strategy, along with two previous strategies, Explanation or Account and Offer of Repair, is the strategies that appear on the more specific demands of the situation, and it requires the presence of two previous strategies.

The other strategy is Alerters. Alerters are elements that serve to inform or attract the attention of Hearer as part of a speech act, for example the nicknames such as "Adam" and others; title such as "Professor"; endearment term as "honey", "sweety", "baby", "sweetheart", and others; the use of "Sir", "Mom", "Bro", "Girl", "Miss"; and also attention getter like "Hey", "Halo" and others.

Downgrading or Attempts to shift consists of several types, including Act innocently or pretend not to notice the offense, for example 'am I late?'; Humor, for example 'You ought to see our fried chicken' that used by speakers as an appeaser or opposed offer repair. This strategy is completely unrelated to the mistake of Speaker, for example 'Let's have a drink' which is spoken by Speaker after making a long wait to Hearer. The next strategy is Concern for the Hearer. This strategy is used as a form of higher concern. Speaker guilty feeling to Hearer makes the Speaker necessary to ensure the feeling of Hearer. This expression like "I hope you did not ......", "Do not worry ...", "Are you okay?".

The forms of the emerging strategy would allow the emergence of a single strategy and any other form that is a combination of up to complex ones. This is a reflection of the situation and also the culture of the speakers. For convenience, the following are examples of data classification:

\footnotetext{
"When you wake up in the morning, you'll have a present waiting for you" (Refinement)

"I'm sorry (IFID), Man(Alerters)

Though you were my friend. (Explanation)

Wanna have some coffees?" (Downgrading)
}

The Apology strategy realization of the native speaker will be different based on the situation, familiar and non-familiar situation. In familiar situation case, the status of the speaker gives impact to how the apology strategy. This status of the speakers is higher than the hearers, equal to hearers, and lower than hearers.

The example of a situation that represents the state of the speaker is higher than hearer in familiar situation is when parents have promised to her son to buy a laptop, but the parents are not able to fulfill their promise due to the prompt meeting in the office. Another example of this status is when a teacher who asks his student to bring a book for him, but the teacher forgets about his student and let the student wait outside his room for 15 minutes.

Based on the data, it is shown that native speakers do not commonly use alerters. In the data, there are also internal modifications, namely intensification as "so sorry". It is to be contrasted with the situation that has many IFID on data. However, it remains the intensification slightly only on one data. This suggests that native speakers are less inclined to use IFID explicitly in apology. They choose to go directly to a specific strategy for the purpose of inserting implicit apology.

What is interesting about the data is the emergence of a single strategy expressed explicitly and directly, which is a strategy of repairs on the first situation. There are some data that represent their single strategy that speakers do not want 
to argue with mistakes that are not made deliberately, until speakers immediately offered a repair over this incident through such utterances, such as "I will have it when I get home," "I will call my friend now. It is also triggered by the awareness of speaker that the mistakes can be fixed directly and quickly so that this strategy becomes very important to use. In addition, repairs strategies appear on each data.

The sentence stating concern to hearer also appear special in the first situation, with utterances like 'I love you' and affirmation to convince hearer with a statement of a promise is a promise, so the effect received by hearer be slightly reduced because of their concern on hearer of the speaker. The concern to hearer also appears specifically in the first situation, with utterances like "I love you" and attempts affirmation to convince hearer with the statement "a promise is a promise", so the effect that is received by hearer is slightly reduced by the concern on hearer from the speaker. Furthermore, the data also expose the attempts to distract or downgrading to neutralize the atmosphere at that time promised to invite meal. This form, belong to the "appeaser" because there is no real connection with the mistakes that have been made.

Then, in the circumstances of the speaker is equivalent to the hearer, the simplicity strategy appears. The first situation when someone asks for help to restore the compact video disc rented to his friend, but it turns out one's friend forget and it results in an additional cost. The second situation when someone asks one's friend to nurture and care for one's fish. However, he is too busy to do it, some of the fish die. Both situations illustrate the difference in the situation, but still demonstrate their familiar context and social status between $\mathrm{S}$ and $\mathrm{H}$.

The first strategy is IFID that does not much appear and its intensification is little. This suggests that the native speakers do not particularly want always to use IFID in every context mistakes made, and it includes the use of the emotions expression strategies. Although the situation is fatal, such as making hearer suffered a loss to the lease payments, and the fish that died due to negligence, it is not enough to make the native speakers have to reveal his guilt by using IFID and other excessive strategies.

The strategy also often appears is the strategy of responsibility. This is consistent with the factors of the situation, which requires the presence of expression of responsibility for mistakes made.Next is the offer repair strategy, as a manifestation of good faith to correct errors that have occurred. Furthermore, native speakers feel no need for expressions of distractions, entertaining or paying attention to hearer for the mistakes that have been made.

The next example is the situation that represents the status of the speaker is lower than the hearer in the familiar situation. A person forgets his promise to buy fruit to his/ her neighbors and the second situation is where someone forgot his promise to the professor. This is a picture of two situations which represent a form familiar situation, but the status of the speaker is lower than the hearer. IFID appears more often and in almost all of the data. Greetings appear only slightly despite the status where the speaker is lower than the hearer, and this situation does not make native speakers use the greeting on his apology speech.

Responsibility speech strategy that often appears indicating that the situation demands the presence of responsibility speech although not always followed by an explanation expression while offer repairs strategy appears quite often. This shows that this strategy is important to appear to remember the mistakes made, like the neighbor and also Professor needs to be corrected immediately to mitigate the effects of hearer due to a mistake made by the speaker. The emergence of the promise of forbearance strategy was necessary to strengthen the narrative purposes. In the data, there are no attempts to shift or concern on hearer.

Similar to familiar situation case, the non-familiar situation, the status of the speaker also gives impact to how the apology strategy. If the status of the speaker is higher than the hearer, this example can represent the situation of the speaker and the hearer. A person who accidentally injures a girl aged about ten years while closing the shop door. Meanwhile, the second situation is an owner of the boutique delivered the wrong color to a costumer the day before.

Based on the analysis, it can be seen that IFID often arises, and it is accompanied by an internal modification of the adverbs like "so sorry" or "really sorry" which indicates that the speaker unintentionally makes the mistakes. Then, the dominant strategy that appears is offer repairs. This is because as a boutique owner who has hurt a buyer, he felt compelled to promptly correct any errors in order to maintain the reputation and also firmness in the boutique. Offer repair strategy is also a result of the factors of the situation, which requires the presence of this strategy. The emergence of responsibility strategy is to state explicitly that he was guilty. However, the explanation strategy does not appear in two situations. This suggests that the native speaker feels no need to provide more arguments for the mistakes he had done.

The next situation when the speaker is equivalent to the hearer. It is represented by the first situation, when someone sees his friend, and he patted on the back, but it turns out that guy is not his friend, jus someone who is similar to his friend. The second situation is the one who sits near a bus window, which was about to get off at the next stop, but a person of the same age sitting beside him thus requiring it to ask permission. Both of these situations show the different circumstances but equally indicate situations that are not familiar and equal social status.

The analysis shows that IFID still appears dominant in a high percentage. This shows that the speaker does not accidentally make the mistake of patting the shoulders of someone who is mistaken for his friend. So this situation in which he is about to ask permission to get off the bus, then the emergence of "excuse me" is important to use. Intensification only rarely emerges in the first situation and not at all on the second situation.

The use of strategies of responsibility, repairs, and the promise of forbearance are not found at all in the data. This is because the situation does not demand the presence of such a strategy. What is interesting here is the attempt to divert concern by conveying a "greeting" on the hearer with speech "Have a great day" as an effort to downgrade of the situation in the second situation. However, in the first situation, there is an attempt to divert concern to the expression of humor or engage in something completely unrelated to the error. The utterances like "Wanna have some coffees?" And "Would you like a beer?" As a manifestation of their efforts to reduce the impact of the mistakes made in the hearer.

The next situation is when a person who boarded the train and realized he had forgotten to bring his wallet and also a ticket. He then tries to answer when the ticket inspector came. While the second situation is a situation where someone is running to catch the bus accidentally bumping into an old woman so that her groceries scattered. 
Both of these situations describe the circumstances in which the speaker and the hearer are not familiar, and status $\mathrm{S}$ is lower than $\mathrm{H}$.

Based on the data, it can be seen the simplicity of the strategies used by native English speakers can be seen. IFID still often appears with very little intensification. An emotional expression used because the situation is so fast and unpleasant to the hearer. The use of emotional expression indicates an element of chance conducted by the speaker on the hearer.

The greetings are used only slightly, namely "Ma'am". It is proved that the native speakers do not frequently use greeting, although the status of the speaker is lower than the hearer. Statement of responsibility appears more frequently though without any further explanation about the mistakes that have been made. However, there are many offer repair strategies, which is used by native speakers to correct the mistakes. There is not any attemptis made to distract the hearer at all.

There is the description of an emerging strategy in a speech situation. If it is concluded, then the following is the average potential emergence of a strategy on the whole situation by native speakers in the speech act of apology, as seen in the following table.

Table 1 The Speech Act of Apology

\begin{tabular}{clc}
\hline No & \multicolumn{1}{c}{ Strategy } & Potency (\%) \\
\hline 1 & Alerters & 25,7 \\
2 & IFID & 76,9 \\
& Intensification & 29,8 \\
& ExpressionEmotion & 21,0 \\
3 & Taking on Responsibility & 46,6 \\
4 & Explanation & 23,3 \\
5 & Offer Repairs & 48,8 \\
6 & Promise of Forbearance & 3,8 \\
7 & Concern to the Hearer & 12,4 \\
8 & Downgrading & 6,1 \\
\hline
\end{tabular}

\section{CONCLUSIONS}

The pattern formed on native English speakers has its own peculiarities.In general, based on the potential occurrences for all situations, the strategy chosen by native speakers tend to be simple. It is based on the potential emergence of IFID followed by repair and responsible in the number of smaller percentage. However, IFID and greetings are not always present in each strategy. It shows the tendency of native speakers to direct on target to achieve communication objectives. Native speakers tend to use the strategy of reduction or diversion efforts, especially in unfamiliar situations.So, for all situations and social levels, native speakers tend to use patterns that are short and direct. Factors that influence the formation or selection of the strategy conducted by native speakers in general are the situation of speech, social status, and themistake rate wherein the greater the impact of the errors that occurred, then the more complex strategyselection that will be taken.

\section{REFERENCES}

Alfattah, M. H. A. (2010). Apology Strategies of Yemeni EFL University Students. Journal MJAL 2 (3), 80.

Bataineh, R. F., \& Bataineh, R. F. (2005). Apology Strategies of Jordanian EFL University Students. Journal of Pragmatic, 38,1901-1927.

Huang, Y. (2007). Pragmatics. New York: Oxfor University Press.

Mastoyo, Y. T. (2007). Pengantar (Metode) Penelitian Bahasa. Yogyakarta: Carasvatibook.

Nadar, F.X. (2007). Penolakan dalam bahasa Inggris dan bahasa Indonesia (dissertation). Yogyakarta: Universitas Gadjah Mada.

Nadar, F.X. (2009). Pragmatik dan Penelitian Pragmatik. Yogyakarta: Graha Ilmu.

Nureddeen, F. (2008). Cross-cultural Pragmatics: Apologies in Sudanese Arabic. Journal of Pragmatics, 40, 279 306.

Nuryanto, A. (2010). Apology Strategies Used in Reader's Letter by Complainee on KOMPAS Daily Cyber-News Issued from January to September 2009 (Master's thesis). Semarang: Universitas Diponegoro.

Ogiermann, E. (2009). On Apologising in Negative and Positive Politeness Culture. Amsterdam: John Benjamins Publising Company.

Smith, N. (2008). I Was Wrong-The Meanings of Apologies. Cambridge: Cambridge University Press.

Ting-Toomey, Stella dan Chung, Leeva C. (2005). Understanding Intercultural Communication. Los Angeles: Roxburry Publishing Company. 